\title{
$\mathrm{PH} 91$
}

\section{Madrid Río, o el retorno de la urbe a la geografía del Manzanares}

\author{
Ginés Garrido Colmenero | Burgos \& Garrido Arquitectos \\ URL de la contribución <www.iaph.es/revistaph/index.php/revistaph/article/view/3883>
}

\section{RESUMEN}

El proyecto Madrid Río es la obra más importante realizada en la ciudad de Madrid en las últimas décadas y, probablemente, uno de los proyectos de espacio público más ambiciosos construidos recientemente en Europa.

En 2003 el Ayuntamiento de Madrid decidió soterrar el tramo del primer gran anillo de circunvalación de la ciudad, que discurría sobre las márgenes de río Manzanares a lo largo de seis kilómetros y cuya construcción, hace 30 años, supuso la desaparición de los vínculos entre la ciudad y su río, que quedó aislado, inaccesible e invisible.

El equipo dirigido por Ginés Garrido y formado por las oficinas Burgos \& Garrido Arquitectos, Porras La Casta, Rubio \& Álvarez-Sala y West 8 ganó el concurso internacional convocado en 2005 para la realización del proyecto de espacio público sobre la superficie, que liberó el soterramiento de la autopista. El proyecto conecta la ciudad de Madrid con los valiosos paisajes exteriores que la circundan y, así, el río Manzanares se ha transformado en el punto de conexión entre la ciudad y su geografía.

Madrid Río ocupa una superficie de $150 \mathrm{Ha}$ de áreas verdes y $6 \mathrm{Ha}$ de equipamientos ciudadanos, instalaciones deportivas, centros de interpretación y creación artística, una playa urbana, áreas de juegos infantiles, quioscos y cafés. Con esta intervención la ciudad de Madrid vuelve a pertenecer a la geografía del río.

\section{Palabras clave}

Ecología | Espacio público | Frente fluvial | Geografía | Infraestructura | Integración | Madrid | Medio ambiente | Paisaje urbano | Parque urbano | Patrimonio | Puentes | Restauración | Río Manzanares | Sostenibilidad social | Transformación | Zonas verdes | 


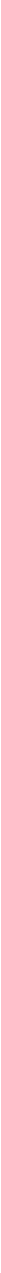

Puente del Rey | foto Ana Müller 
1

Autores del proyecto: Burgos \& Garrido (Francisco Burgos, Ginés Garrido); Porras La Casta (Fernando Porras-Isla, Arantxa La Casta); Rubio \& Álvarez-Sala (Enrique Álvarez-Sala, Carlos Rubio); West8 Urban Design \& Landscape Architecture (Adriaan Geuze, Edzo Bindels). Director: Ginés Garrido.

Vista aérea parque de Arganzuela | imagen aérea editada por los autores del proyecto

\section{UN PROYECTO URBANO HOLÍSTICO, LO INCLUYE TODO}

Madrid Río ${ }^{1}$ es un proyecto urbano de gran escala que recorre una significativa franja de la ciudad. Su dimensión y su alcance comprometen al tejido urbano en toda su dimensión, afectando a su completo metabolismo. Es una intervención que recorre desde los más profundos niveles funcionales subterráneos, hasta los elementos de nueva continuidad en superficie.

El proceso ha integrado diferentes planos que incluyen los nuevos elementos de movilidad urbana (40 km de túneles con más de 200.000 vehículos diarios), el soterramiento de las líneas eléctricas que transportan el $40 \%$ de la energía de la ciudad, la renovación completa de la recogida y filtración de aguas de lluvia, la protección contra inundaciones, la nueva conexión entre barrios mediante la construcción de 21 puentes, y la ordenación de un espacio verde público unitario de más de 150 hectáreas.

Es el proyecto más ambicioso y complejo y múltiple jamás construido en Madrid, y ha incorporado a todas las disciplinas técnicas y actores de una ciudad en marcha que ha afectado positiva y directamente a una población superior a 1.200 .000 de habitantes.

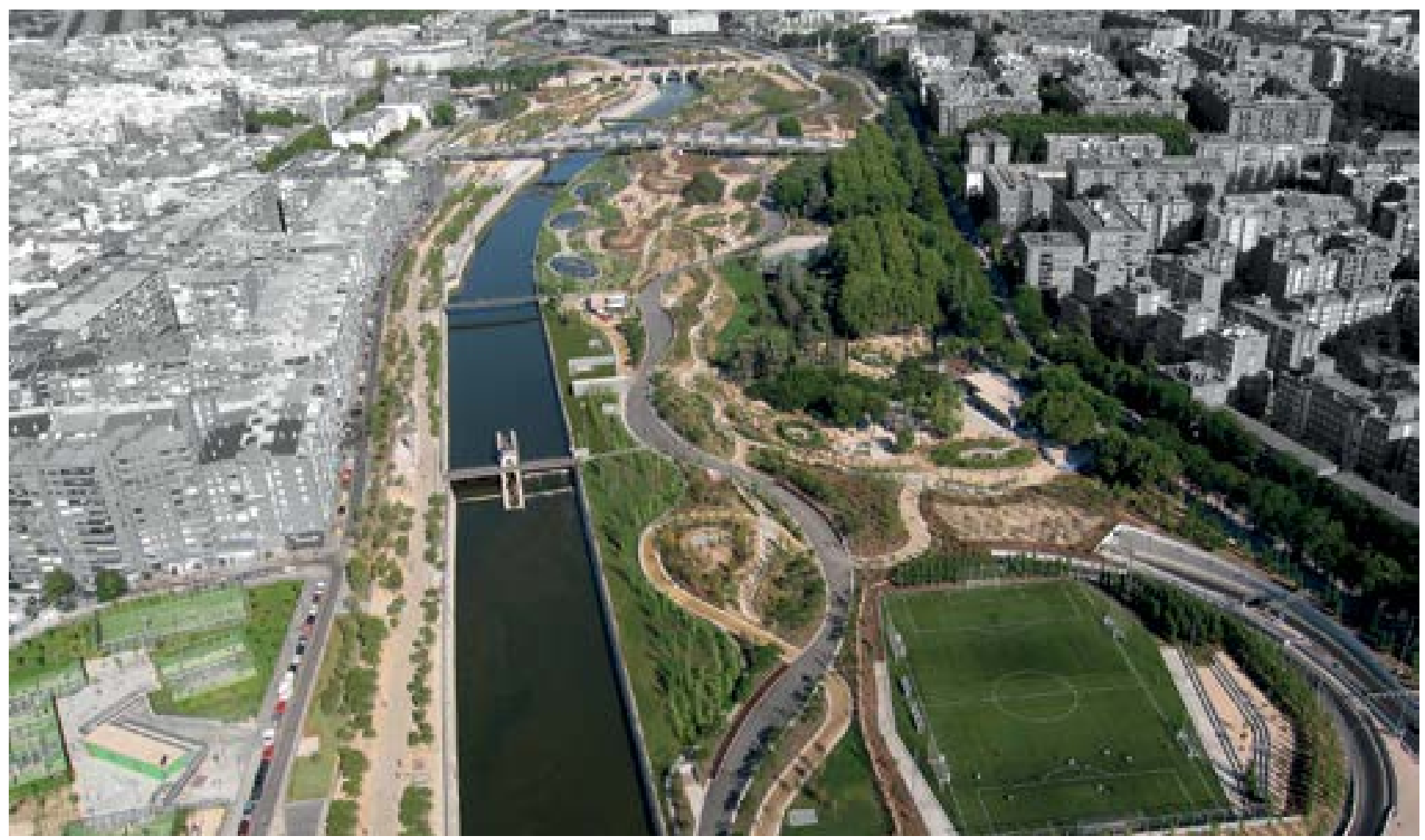




\section{ECONOMÍA AL SERVICIO DE LO PÚBLICO}

Los recursos económicos empleados en la totalidad del proyecto, unos 3.600 millones de euros en obras de ingeniería urbana y cuatrocientos veinte millones de euros en las obras de diseño urbano, fueron aportados por el Ayuntamiento en un $80 \%$ a través de su capacidad de endeudamiento. El diseño imaginativo, riguroso y bien construido de ingeniería financiera, realizado por el equipo económico-administrativo, permitió al equipo municipal, contrariamente a lo que se ha difundido en los medios de comunicación, articular las cargas financieras de acuerdo a la potencia económica de la ciudad, con un producto interior bruto de más de doscientos treinta mil millones de euros.

Lo más importante, y excepcional, es que la totalidad de los recursos económicos fueron empleados en la construcción de infraestructuras y espacios públicos, sin ningún retorno económico por venta de activos. Las mejoras urbanas en su mayoría han sido destinadas a los barrios más desfavorecidos, que sufrían la terrible agresión de la autopista, el abandono del río, la desconexión con el centro, la escasez de dotaciones, el deterioro del tejido urbano y la inexistencia de un espacio público de calidad.

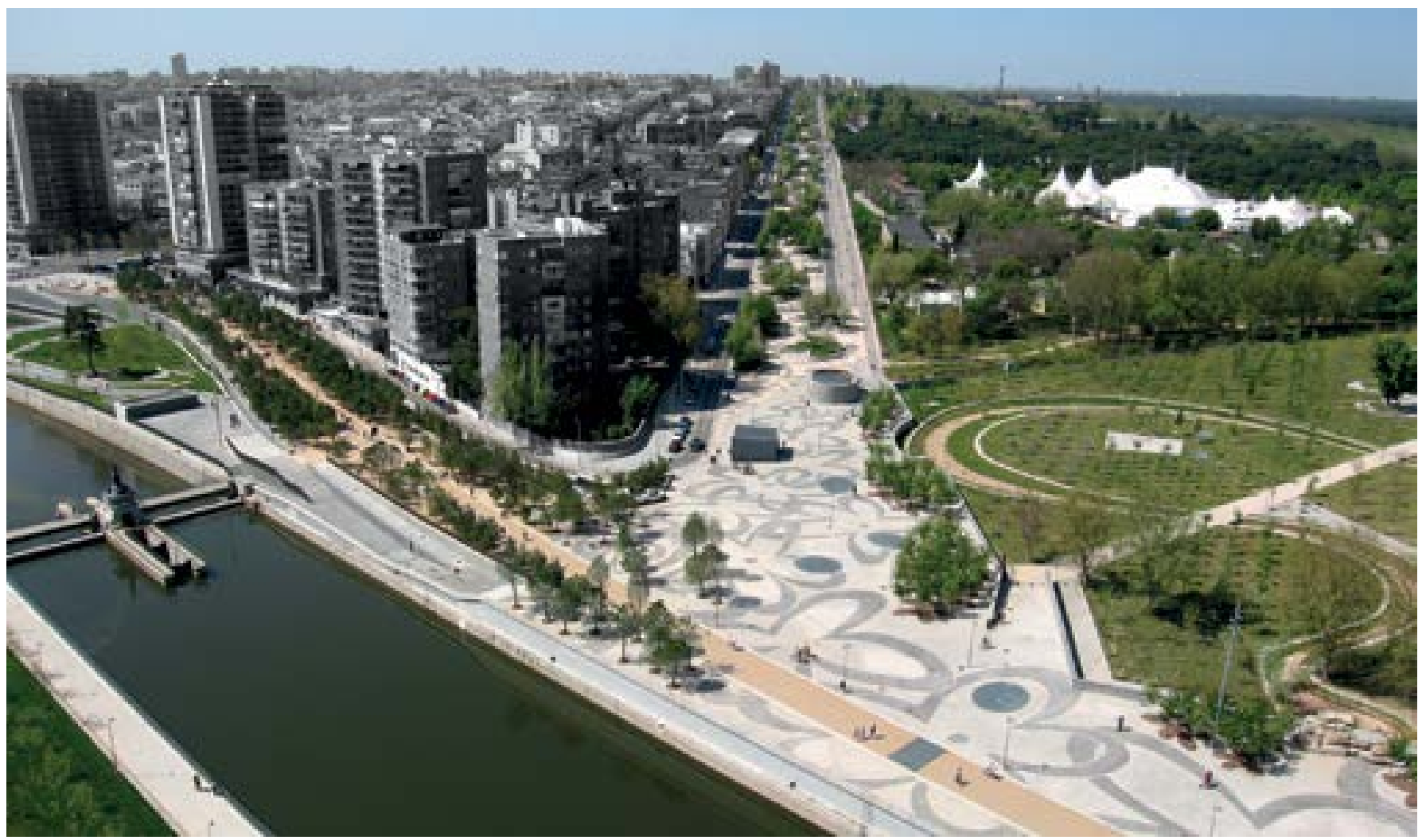




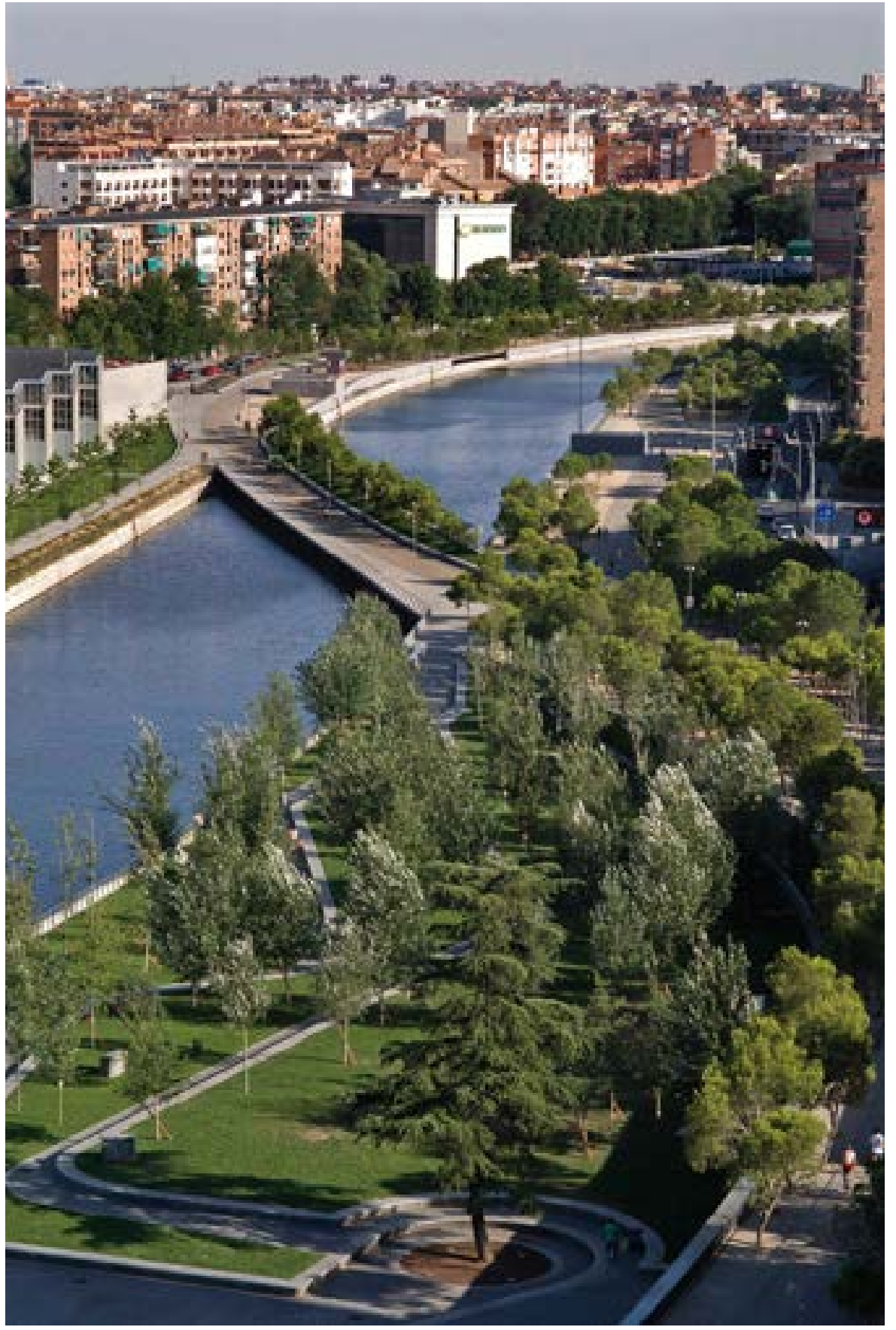

Puente Oblicuo | foto Ana Müller 


\section{DETERMINACIÓN POLÍTICA Y RESPONSABILIDAD TÉCNICA}

El proyecto fue posible gracias la firme determinación del entonces alcalde de la ciudad, Alberto Ruiz Gallardón, que apoyado en sus equipos y confiado en la capacidad de las principales empresas constructoras del país, fue capaz de asumir grandes riesgos.

El alcalde contó con tres equipos: el equipo económico-administrativo, el equipo de ingenieros y el equipo de arquitectos dedicados al diseño urbano. Los equipos trabajaron con gran libertad pero bajo una intensa exposición mediática y una gran presión por cumplir los plazos, muy reducidos, por lo que estuvieron sometidos a una enorme tensión política que les obligaba a llegar más allá de sus responsabilidades específicas. Se trabajó sin embargo con gran convicción en la importancia, el carácter innovador y la transcendencia para la ciudad del resultado, en un proceso muchas veces al límite de la ciencia.

\section{TERRITORIO Y GEOGRAFÍAS}

La estrategia de enterrar la autopista que cruzaba la ciudad a lo largo de las orillas del Manzanares ha desvelado una oportunidad que supera el alcance urbano del proyecto. La intervención adquiere una dimensión territorial que en realidad se relaciona con la cuenca completa del Manzanares, de más de $70 \mathrm{~km}$. La escala del proyecto tiene la capacidad de enlazar física, cultural, visual y conceptualmente los paisajes del exterior de la ciudad con los bosques y las sierras, en el norte, y las mesetas y vegas del sur. A través del río que se convierte en un conector eficaz, la geografía, sobre la que se asienta Madrid y que había quedado oculta bajo el trazado de las infraestructuras urbanas y el tejido construido, se revela y emerge.

El proyecto ha incorporado esta conciencia geográfica y ha dialogado con los recursos biológicos del paisaje del río, de una variedad máxima, con altitudes que varían desde los $2.200 \mathrm{~m}$ en su nacimiento hasta los $410 \mathrm{~m}$ de su desembocadura. De este modo, el diseño del espacio público se ha nutrido de este imaginario haciéndolo reaccionar con las particularidades urbanas.

\section{ESPACIO PÚBLICO COMO AGLUTINANTE SOCIAL}

El proyecto se apoya en la dimensión lineal del río, que tiene tres circunstancias favorecedoras de su condición de catalizador social. Por un lado su continuidad, que permite enlazar y conectar los barrios del noroeste, con una población de una renta per cápita de $30.000 €$, con los del suroeste donde se 
localizan las poblaciones más desfavorecidas, con un gran índice de inmigración y una renta de $17.000 €$. En segundo lugar la gran capacidad de contacto de sus dos fachadas de más de $6 \mathrm{~km}$, que permiten una participación intensa de los vecinos de seis distritos. Por último la cualidad de conexión transversal con los nuevos puentes que ha aproximado, de forma efectiva, los barrios entre sí.

Todos sus habitantes, de distinto modo, usan al tiempo el nuevo espacio público. El parque ha cubierto la enorme carencia de zonas verdes y ámbitos abiertos de acceso libre, existente hasta ahora en las áreas del sureste y suroeste, en la corona exterior de Madrid, pero también en el centro urbano donde los barrios son muy densos y compactos y las operaciones de esponjamiento son difíciles, socialmente muy conflictivas, costosas y largas en el tiempo.

\section{ÁGORA PÚBLICA, PARA TODOS}

Además de sus cualidades como espacio verde para el paseo y el ocio, el proyecto incluye 8 instalaciones deportivas en una superficie de $6 \mathrm{Ha}, 15$ jue-

Salón de Pinos | foto Jeroen Musch

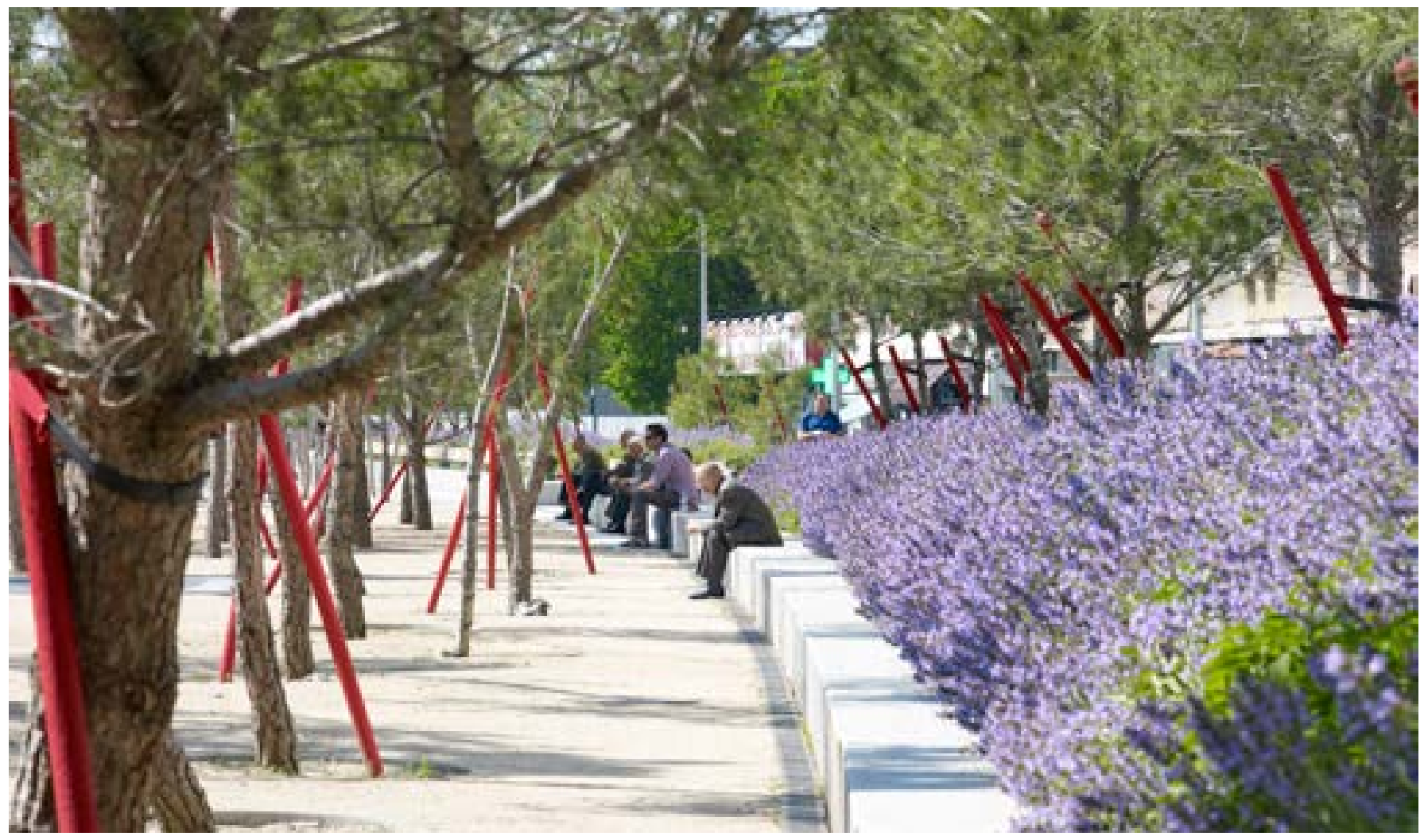


gos infantiles, $28 \mathrm{~km}$ de carril bici, dos restaurantes, 6 cafés y dos superficies libres para diversos eventos.

Así mismo, dentro de sus límites incluye el Centro de Creación Contemporánea Matadero Madrid, (www.mataderomadrid.org) en el que se han restaurado las instalaciones del antiguo matadero de la ciudad, construido entre 1912 y 1925.

Este conjunto es un gran laboratorio para la creación contemporánea multidisciplinar, estrechamente vinculado a la participación ciudadana, que actúa como catalizador social y cultural, que tiene más de 1.000 .000 de visitas anuales y programa más de 4.000 actividades.

En el conjunto funcionan de forma independiente pero simultánea dotaciones como cine, teatro, biblioteca, centro de diseño, vivero de proyectos ciudadanos, factoría cultural, salas de exposiciones, etc. También alberga la sede de la Compañía Nacional de Danza. Matadero es un referente mundial en la gestión de espacios para la innovación y la alta cultura y ha conformado un escenario activo a disposición de la iniciativa de los ciudadanos y las asociaciones vecinales.

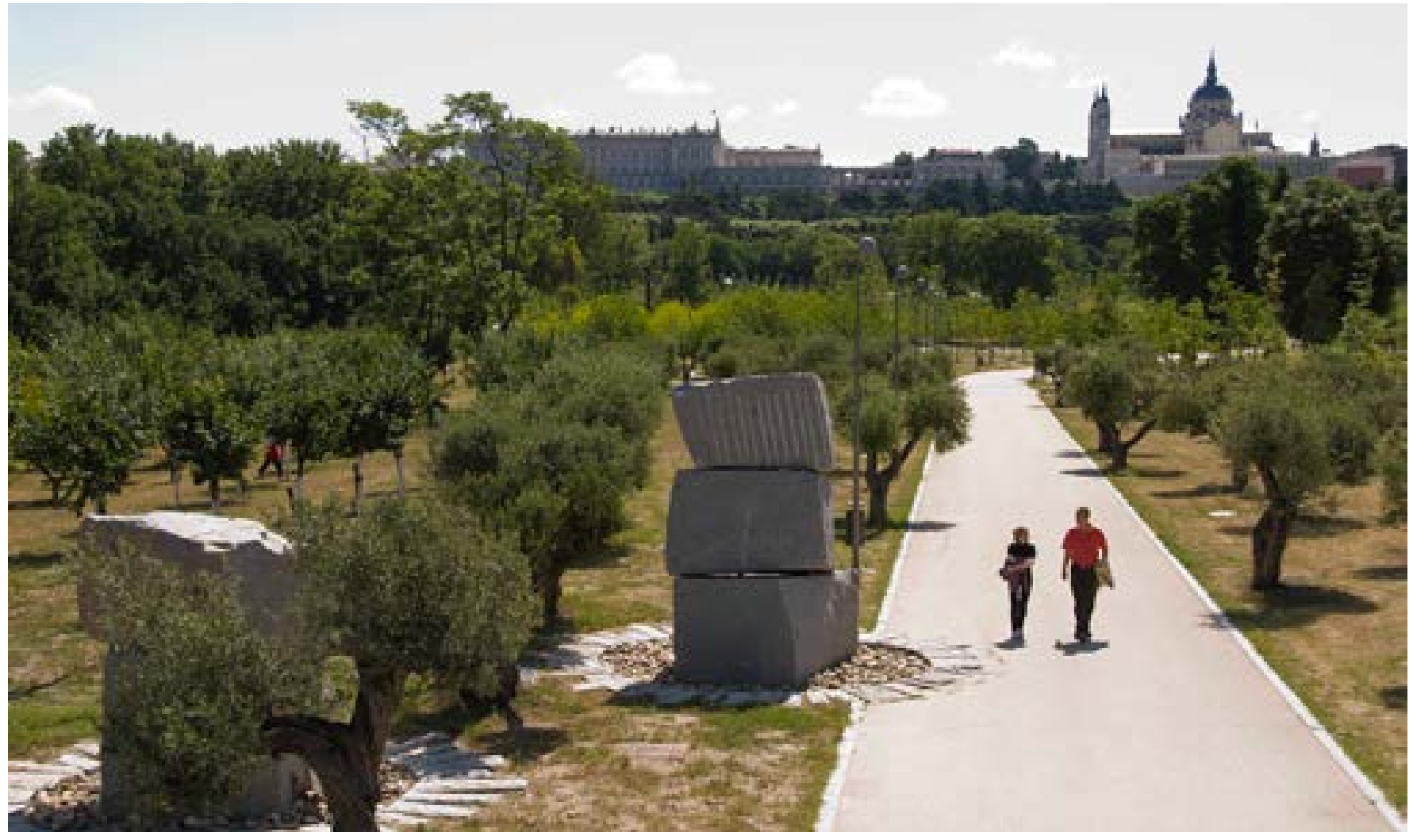




\section{ECOLOGÍAS URBANAS}

El entorno sobre el que se ha desarrollado el proyecto es un tejido urbano complejo, completamente consolidado, que atraviesa la ciudad en una de sus partes más densas, de norte a sur. El carácter central de la operación no solo implica a una gran cantidad de población directamente afectada, sino a los servicios más importantes de la ciudad, sus instalaciones y sus líneas de transporte.

Además los trabajos de integración de las orillas del río se producen en contacto con las estructuras de cubierta de los túneles e integran todos sus mecanismos de funcionamiento: accesos y rampas, filtros de aire, ventiladores, salidas de emergencia, cuartos eléctricos, entre otros. Por tanto, no cabe duda de que la estrategia empleada para la construcción del espacio público ha tenido en cuenta su pertenencia a un sistema ecológico eminentemente urbano y artificial.

A pesar de esto, el proyecto se transforma en un corredor verde, gracias a que el principal material utilizado es la vegetación, con la plantación de más de 35.000 árboles autóctonos adultos, especialmente seleccionados, más de 2.000 árboles de pequeño porte y alrededor de 400.000 arbustos relacionados con la flora presente en la geografía madrileña.

Es un proyecto artificial construido con la naturaleza. El enfoque del proyecto ha estado subrayado por una conciencia medioambiental, basada en la utilización de recursos renovables y la adecuación apropiada de los medios empleados tanto en su construcción como en su mantenimiento.

Se ha prestado un especial cuidado en la gestión de las grandes cantidades de tierra generada al abrir los túneles, reutilizándola en la nueva topografía necesaria para modelar el parque.

Los materiales destinados a la generación del espacio público han sido elegidos en función de su producción en ámbitos próximos a la obra. Las dos grandes familias de materias primas necesarias para la ejecución mayoritaria de los espacios han sido el granito natural, presente en las canteras del centro de la Península Ibérica, y la vegetación de carácter forestal, extraída de campos y viveros de los países mediterráneos. La cantidad de materia vegetal aportada ha ayudado a fijar grandes cantidades de $\mathrm{CO}_{2}$, constituyendo un nuevo pulmón de la ciudad.

Ha sido fundamental diseñar un sistema de riego, basado en la recuperación del agua regenerada de las depuradoras de la ciudad y de los drenajes de las líneas del metro. Todo el parque ha sido concebido para reciclar este tipo de agua. 


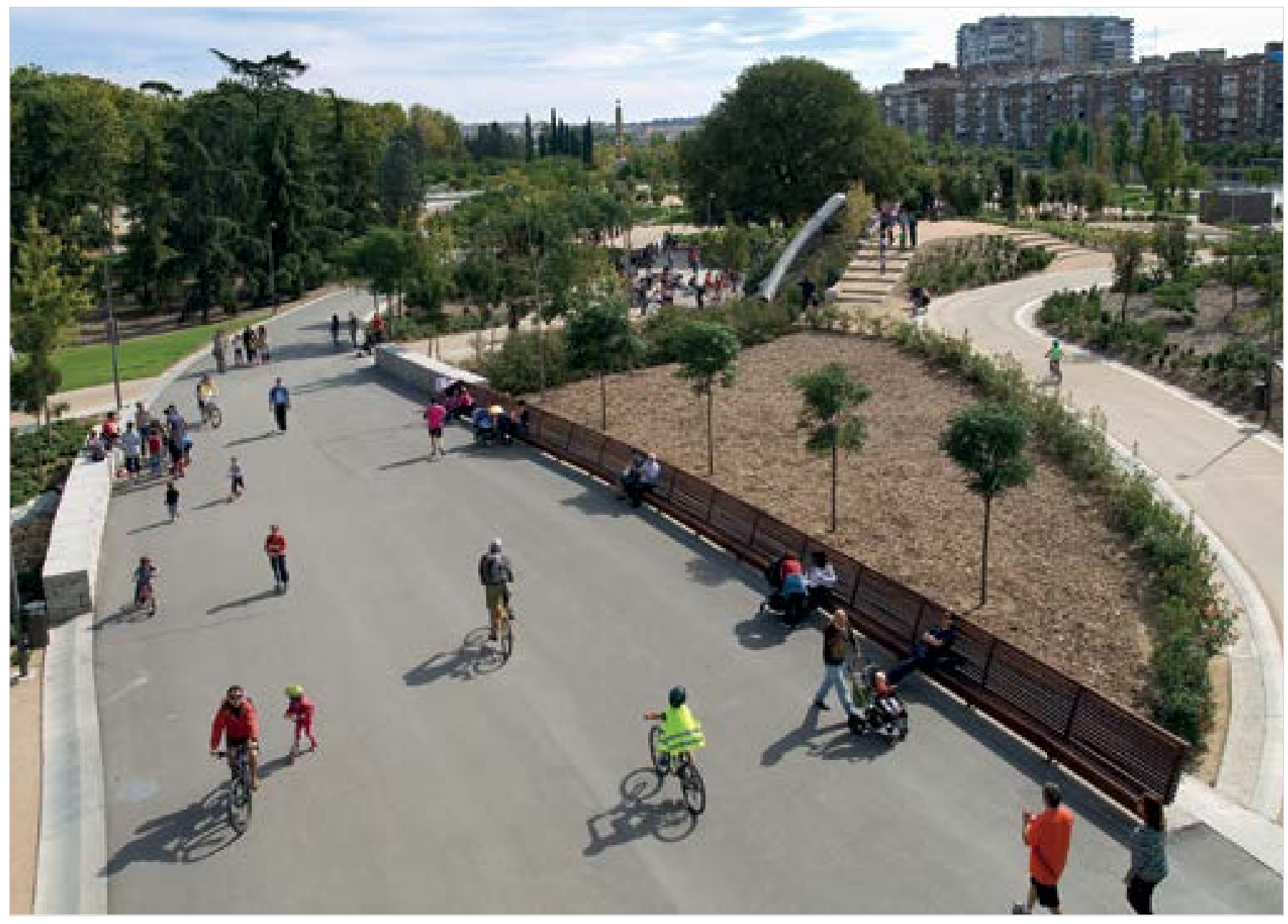

Parque de Arganzuela | foto Ana Müller

\section{RECICLAJE DEL PATRIMONIO INDUSTRIAL HIDRÁULICO}

La presencia del río Manzanares como parte fundamental del proyecto tiene que ver con la rehabilitación de todos los elementos de control hidráulico de su cauce.

El río es un sistema canalizado y controlado por siete presas urbanas. Este conjunto fue construido en la década de los años 50 del siglo XX y tanto los muros cajeros que recorren las dos orillas a lo largo de algo menos de $5 \mathrm{~km}$, como las presas, se llevaron a cabo con un proyecto unitario y unos materiales presentes en la ciudad desde su fundación, los mismos con los que, por ejemplo, se edificó el Palacio Real.

El carácter homogéneo de estas piezas y su calidad constructiva aportan una gran unidad al paisaje fluvial urbano. 

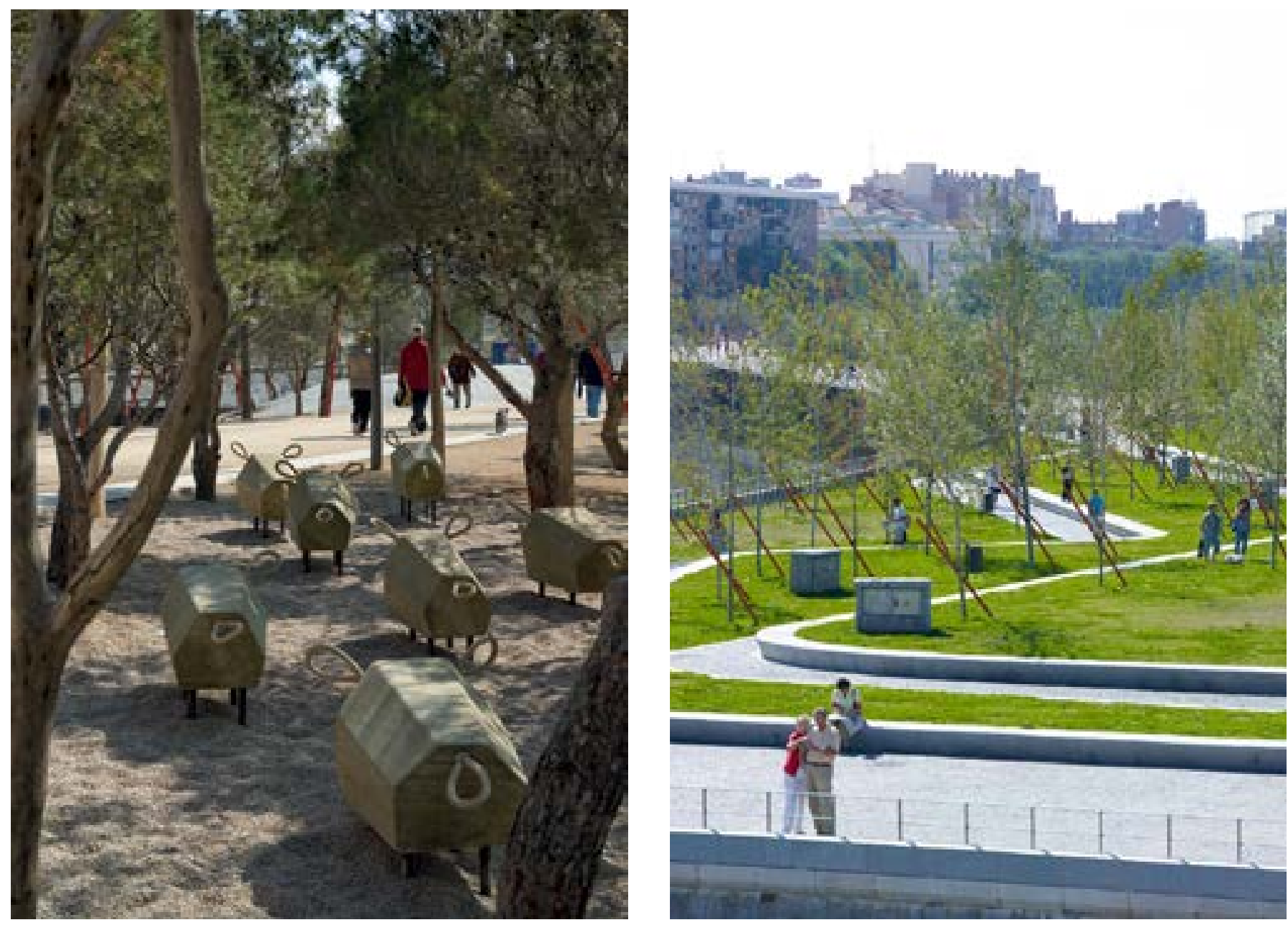

Juegos infantiles | foto Ana Müller

Paseando por Madrid Río | foto Jeroen Musch

El proyecto Madrid Río ha incluido la restauración de estos elementos y su reciclaje para usos públicos, sin perder sus funciones infraestructurales. También ha incluido la reutilización de un puente de la antigua autopista en un paso arbolado para peatones y ciclistas.

Dentro de las obras de recuperación del patrimonio industrial en su área de influencia, el proyecto incluye la rehabilitación del antiguo Matadero, una micro ciudad reciclada en Centro de Creación Contemporánea.

\section{RESTAURACIÓN DE LAS ARQUITECTURAS HISTÓRICAS}

Madrid Río ha incluido como parte fundamental de su alcance, la restauración de los más importantes elementos históricos vinculados al el paso del río. La integración urbana de los principales puentes históricos, que estuvie- 


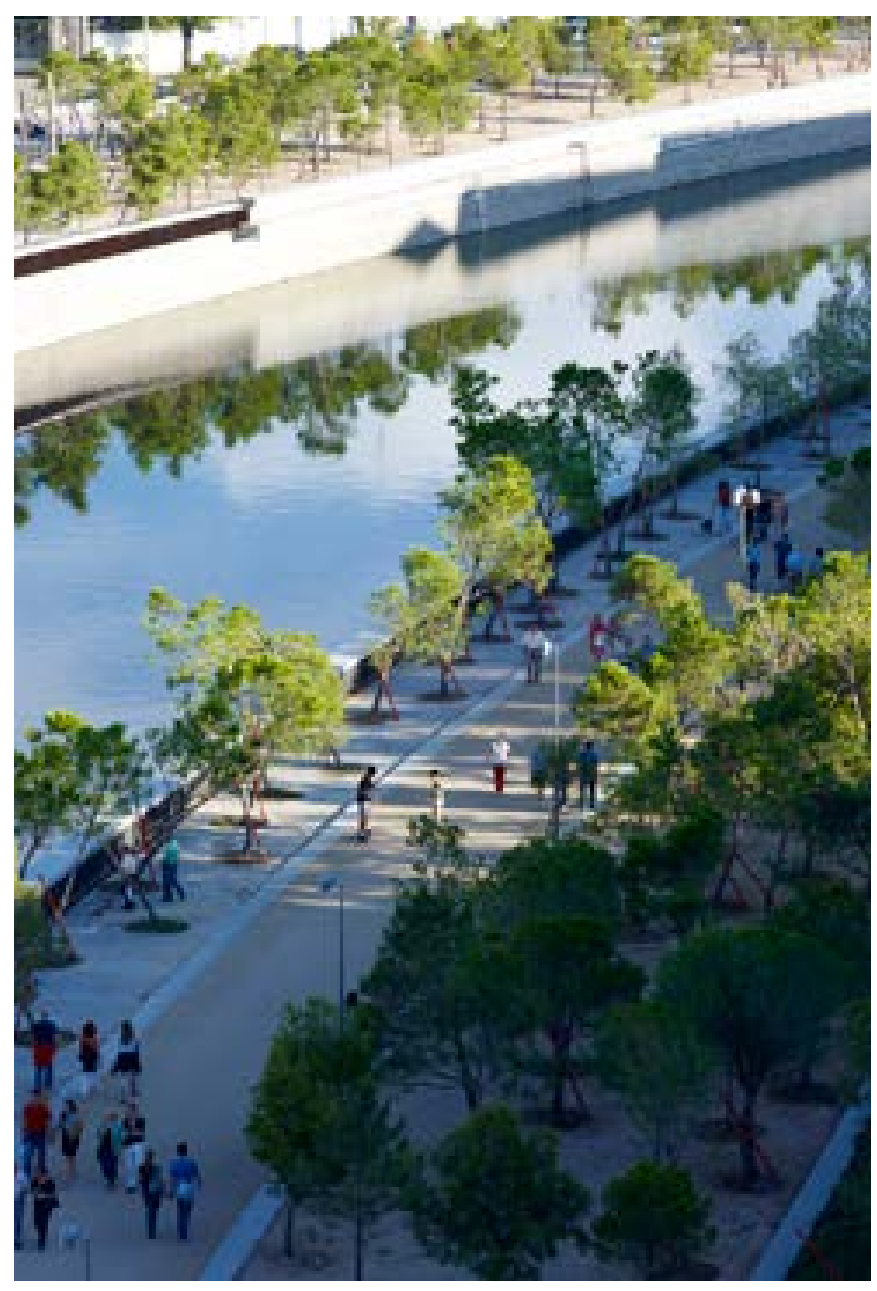

ron ligados en el pasado a los caminos de conexión con las ciudades próximas de fundación romana, ha sido uno de los objetivos del proyecto.

Las obras de rehabilitación no solo han afectado a las estructuras históricas, puente de Segovia (1584), puente de Toledo (1832), puente del Rey (1828), sino a su entorno amplio, de modo que se han conformado nuevos escenarios de relación entre los monumentos y la ciudad. En este contexto de recuperación del patrimonio histórico el proyecto ha actuado también en el entorno de la ermita de la Virgen del Puerto (1725) y en el acceso a la Casa de Campo (1561), parque de caza de la dinastía de los Habsburgo, convertido en una huerta de frutales de uso público.

La conexión de Madrid Río con el centro de la ciudad, que se ha desarrollado en el entorno y jardines del Palacio Real y la primera estación de ferrocarril de Madrid (1880), ha renovado la forma de enlazar la ciudad histórica y el río. 


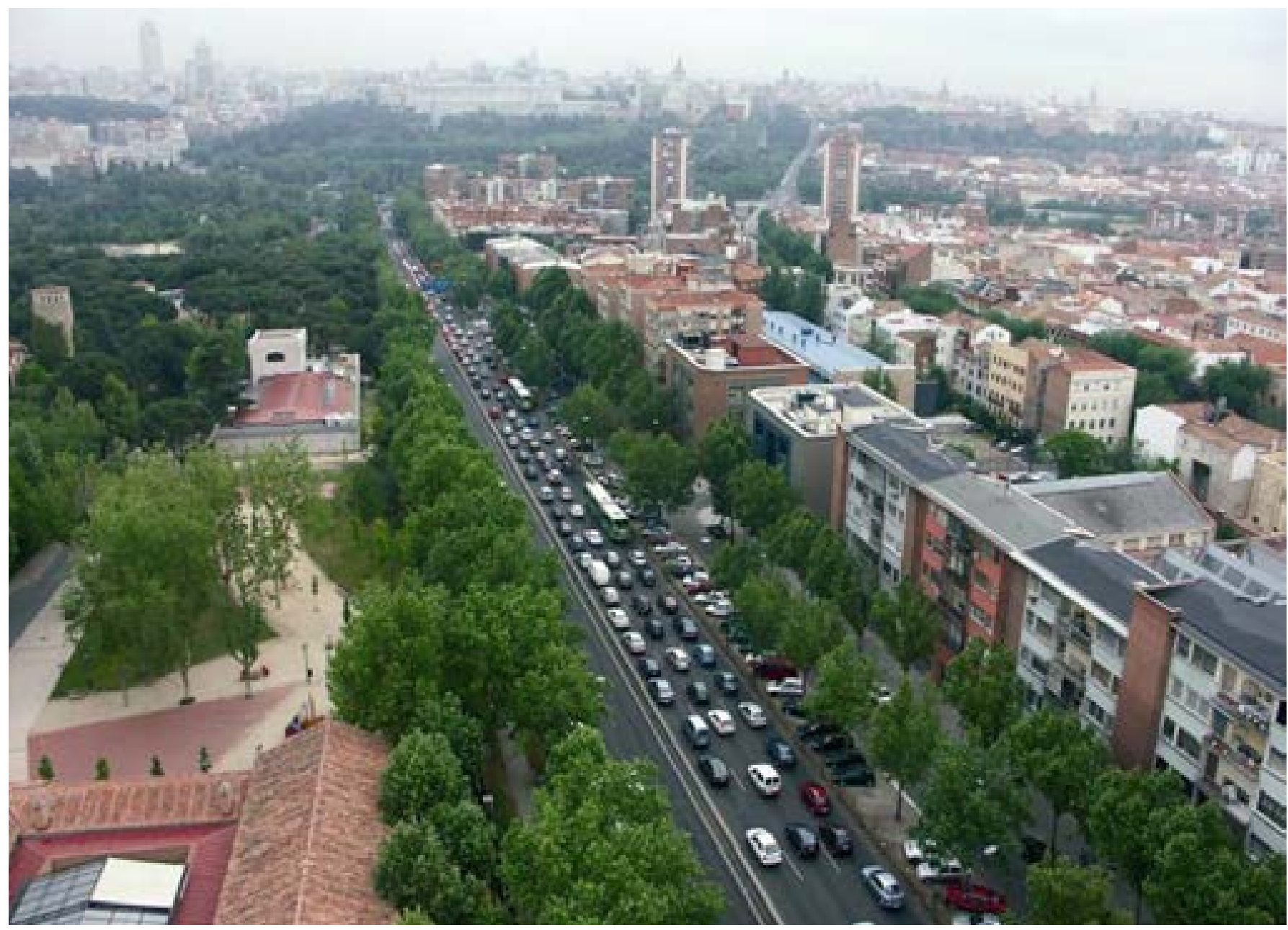

Avenida de Portugal antes de la intervención | foto Ayuntamiento de Madrid

\section{APROPIACIÓN E IDENTIFICACIÓN CIUDADANA}

El proyecto en sus primeras etapas sufrió un importante rechazo de gran parte de la población.

El soterramiento de la autopista, que duró algo más de tres años, constituyó un enorme conjunto de molestias, producidas de una parte por las incidencias del tráfico de automóviles, que se mantuvo operativo durante la ejecución de las obras, y de otra por los efectos ambientales, muy negativos, soportados por el vecindario, que estuvo en contacto directo con los complejos trabajos.

En estas condiciones el proyecto era arriesgado y difícil de explicar. Como consecuencia, contó con un periodo inicial de oposición política y fue cuestionado por parte de amplios sectores de la izquierda social. 


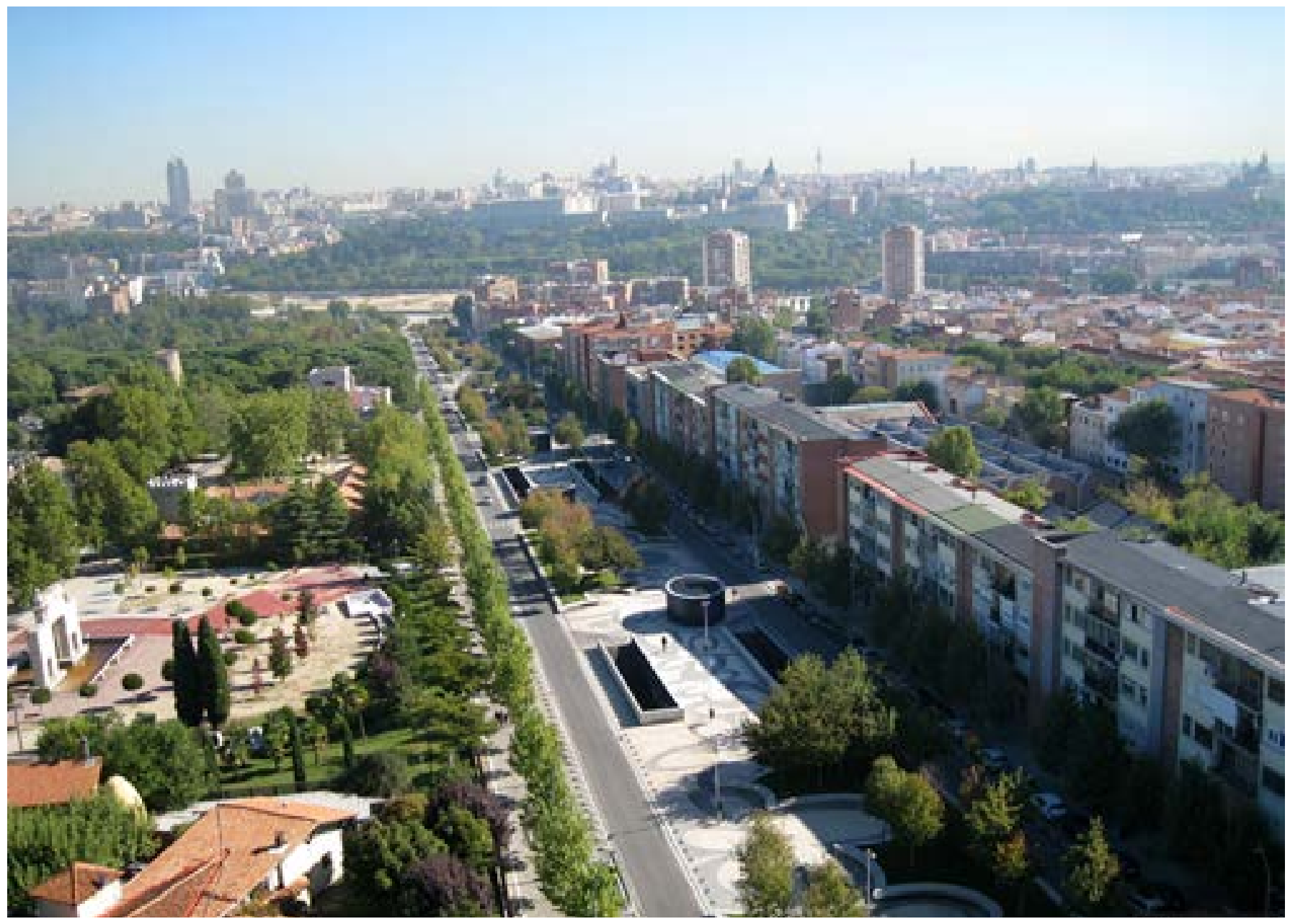

Avenida de Portugal después de la intervención | foto Ayuntamiento de Madrid

Sin embargo, una vez concluido el primer periodo de construcción, que culminó con la apertura de los túneles el año 2007, la percepción de los ciudadanos comenzó a transformarse en aceptación de la operación. Cuando los trabajo sobre el espacio público fueron finalizando, los ciudadanos se apropiaron progresivamente de él, hasta llegar a utilizarlo de manera muy intensiva.

Actualmente la identificación con el resultado, y la sensación de pertenencia de la población que vive en las inmediaciones, es un hecho. De momento, los vecinos mantienen su residencia en este lugar, que aprecian y con el que se identifican.

El reto a partir de ahora es minimizar la gentrificación y tratar de enriquecer la fábrica urbana con procesos que introduzcan una mayor calidad edificatoria en este espacio. 


\section{PATRÓN UNIVERSAL Y LOCAL}

En la última década se han realizado muchas intervenciones urbanas ejemplares en bordes fluviales y marítimos, como en Seúl, París, Ljubljana, o Barcelona; algunas intervenciones han supuesto una superposición de usos, como el Olympic Sculpture Park en Seattle, o el Rose Fitzgerald Kennedy Greenway en Boston. Muchas de ellas han integrado de un modo nuevo las grandes infraestructuras viarias. Son intervenciones de escala territorial que construyen nuevas ecologías. También hemos asistido a actuaciones inteligentes y sostenibles sobre la movilidad urbana, como en Oporto o Medellín, proyectos de peatonalización, como Estrasburgo; y, por supuesto, hermosos parques urbanos que incorporan actividades y dotaciones. Pero hay muy pocas ocasiones en las que esto se ha producido al tiempo en una secuencia de capas físicas, procesuales, temporales y sistemáticas, "una sobre otra" en total integración. Esto ha ocurrido en Madrid.

Y por ello Madrid Río se ha transformado en un patrón universal sobre cómo acometer este tipo de intervenciones en otras ciudades en el mundo.

Pero la realización concreta y material, incluso la filosofía del proyecto, también se ha convertido en un modelo para la ciudad de Madrid, que ha tomado partes importantes de su diseño y de sus detalles como ejemplo, y ahora constituyen una suerte de catálogo del "buen hacer" de la ciudad.

\section{UN LUGAR ESPECÍFICO}

Desde su inauguración Madrid Río se ha convertido en uno de los principales iconos de la ciudad. Su gran accesibilidad, y su capacidad de enlazar áreas verdes o habitadas antes inconexas, lo ha convertido en un elemento visible a pesar de su carácter horizontal, ligado a la superficie. Su capacidad de acogida y atracción ha superado los intereses de los barrios limítrofes, y ha adquirido de forma casi inmediata un valor como condensador metropolitano.

Su diseño unitario y completo, que abarca desde las estrategias urbanas hasta los detalles locales, sin especiales estridencias pero atento a las particularidades urbanas, lo ha dotado de una imagen reconocible que se puede comprender con facilidad. Por estas razones, entre otras, ya ha sido incluido en las guías de la ciudad, junto al Museo del Prado, el parque del Retiro o los barrios históricos de los Austrias. Como contraste con éstos, Madrid Río se presenta como exponente real de la ciudad futura. De este modo se percibe como un fenómeno singular, que ha pasado a formar parte del imaginario de los ciudadanos y de los visitantes, de manera inmediata, a pesar de encontrarse en un medio urbano complejo y multifacético como es Madrid. 


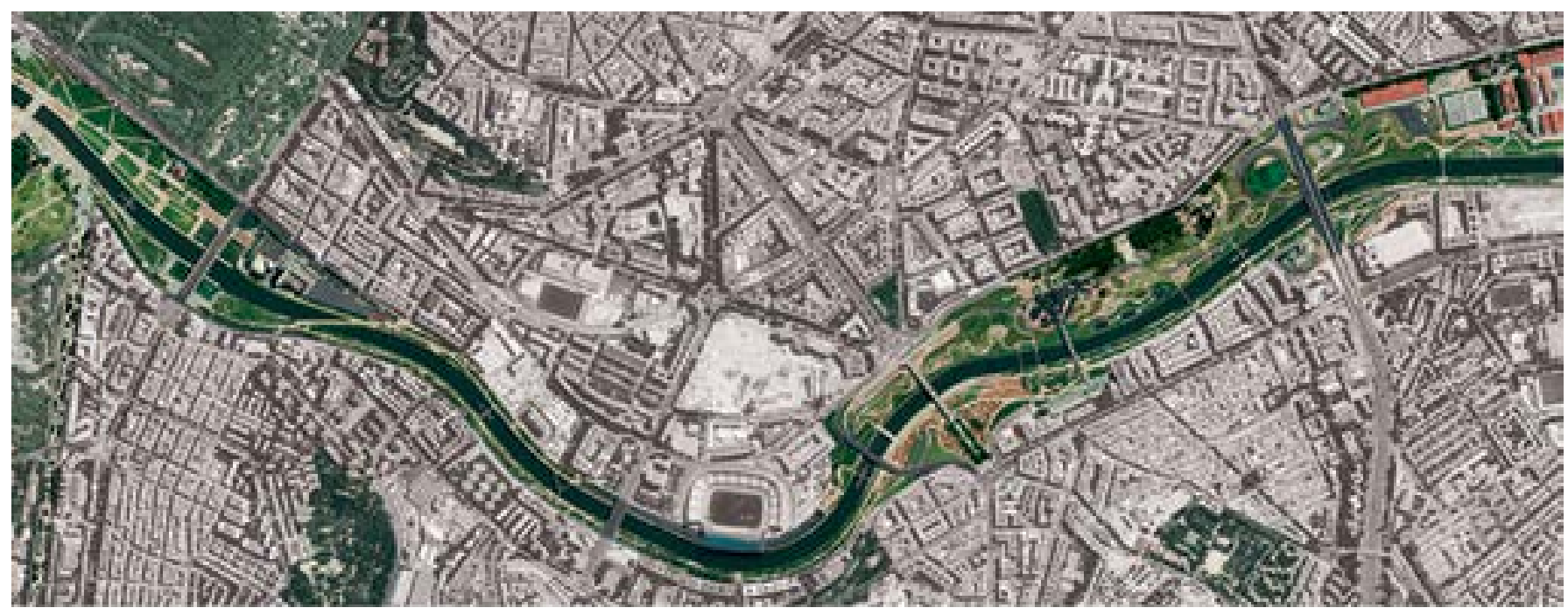

Vista aérea Madrid Río | imagen aérea editada por los autores del proyecto

MADRID RÍO

\section{DATOS BÁSICOS DEL PROYECTO DE ARQUITECTURA Y URBANISMO}

Localización: Madrid

Promotor: Ayuntamiento de Madrid

Presupuesto: $420.000 .000 €$

Fechas: 2005-2015

Superficie (Urbanización): 150 hectáreas

(50 hectáreas ejecutadas sobre los túneles de la M-30)

Superficie (Plan Especial): 820 hectáreas

Distritos afectados: 6

Parques y jardines: 150 hectáreas

Aceras: 13 hectáreas

Calzadas: 5 hectáreas

Otros usos: 2 hectáreas

Longitud de sendas peatonales y ciclistas: $10 \mathrm{~km}$

N. ${ }^{\circ}$ de puentes y pasarelas de nueva

construcción: 12
N. ${ }^{\circ}$ de presas rehabilitadas: 7

$\mathrm{N} .^{\circ}$ de puentes reciclados: 1

N. ${ }^{\circ}$ de puentes restaurados: 5

N. ${ }^{\circ}$ de puentes ampliados: 2

N. ${ }^{\circ}$ de árboles plantados: 33.500

N. ${ }^{\circ}$ de arbustos plantados: 460.000

N. ${ }^{\circ}$ de instalaciones deportivas de nueva creación: 8

N. ${ }^{\circ}$ de instalaciones deportivas restauradas: 2

N. ${ }^{\circ}$ de áreas infantiles: 15

N. ${ }^{\circ}$ de circuitos biosaludables: 2

N. ${ }^{\circ}$ de fuentes ornamentales de nueva creación: 24

$\mathrm{N} .^{\circ}$ de fuentes ornamentales restauradas: 1

N. ${ }^{\circ}$ de edificios construidos: 12 


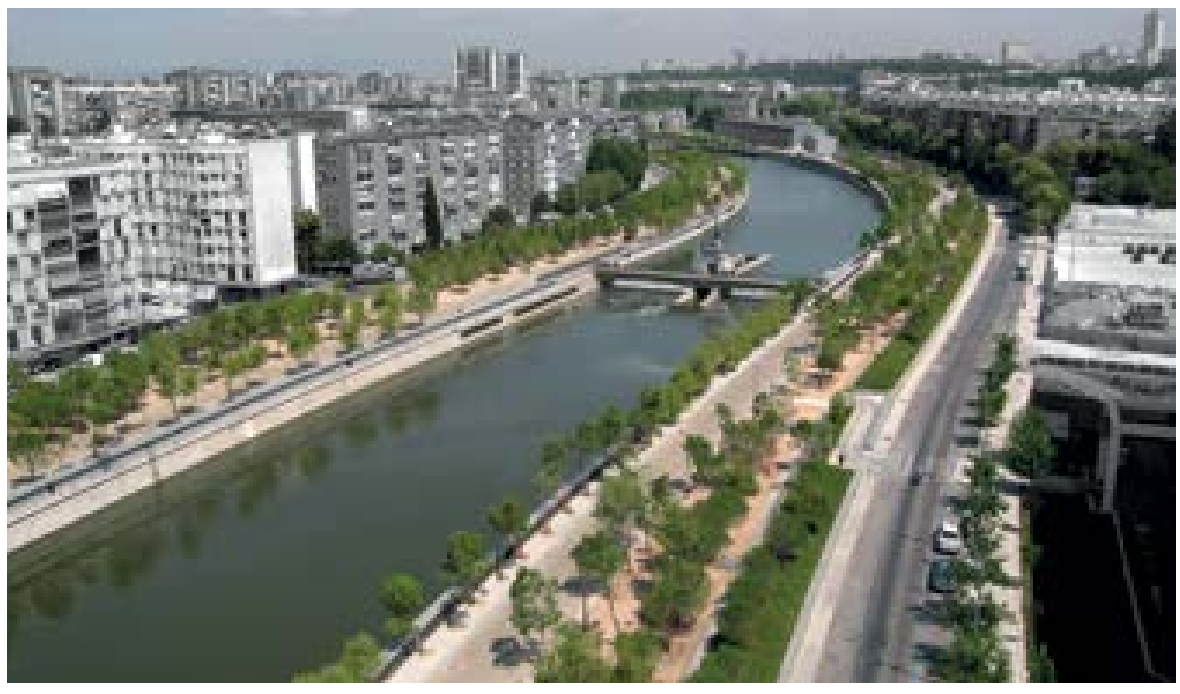

Recuperación del patrimonio hidráulico | foto Ayuntamiento de Madrid

\section{MADRID RÍO COMO CASO DE ESTUDIO}

La repercusión social de Madrid Río se ha visto complementada con una atención de los medios académicos por el proyecto. Aunque su repercusión en los foros internacionales no es extraordinaria, a pesar de que ha sido portada dos veces en el New York Times, primero el parque y después el Centro de Creación Contemporánea Matadero, las escuelas de arquitectura y las escuelas de posgrado han mostrado mucho interés por el fenómeno político, económico, urbano y social que ha supuesto el proyecto en el contexto de una capital europea destacada como Madrid.

A pesar de que el grueso de las obras se finalizó en el otoño de 2011, año tras año se incrementan las visitas de diversos centros académicos de todos los continentes. La magnitud y complejidad del proyecto hace difícil su comprensión como proceso integrado y su análisis riguroso como caso de estudio, solo es posible a través de una experimentación directa en el sitio, y de la consulta con los múltiples agentes que se implicaron en su desarrollo.

El proyecto ha recibido en los últimos años diversos premios nacionales e internacionales que han valorado sus múltiples ventajas como nueva gran pieza de la ciudad. Entre los premios recibidos cabe destacar el XII Veronica Rudge Green Prize in Urban Design, otorgado por la Universidad de Harvard en 2016. Es probablemente el más importante que se otorga en el mundo a proyectos de diseño urbano y se concede a aquellos construidos en los últimos diez años que destacan por la excelencia de su diseño y por su capacidad para transformar las ciudades mediante intervenciones planteadas con estrategias socialmente responsables que mejoran el espacio público y la calidad de vida de sus ciudadanos. 


\section{BIBLIOGRAFÍA}

- BURGOS, F; GARRIDO, G; PORRAS-ISLA, F. (2014) Paisajes en la Ciudad. Madrid Río: geografía, infraestructura y espacio público. Madrid: Turner, 2014

- BURGOS, F; GARRIDO, G; PORRAS-ISLA, F. (2011) Madrid Río. Un proyecto de transformación urbana. Madrid: Turner, 2011 